\title{
A importância da banana pacovã verde como alimento funcional para a saúde
}

\section{humana}

The importance of the green pacovan banana as a functional food for human health

La importancia del plátano pacovan verde como alimento funcional para la salud humana

Recebido: 29/10/2021 | Revisado: 07/11/2021 | Aceito: 10/11/2021 | Publicado: 13/11/2021

Daysiane Mota Lima

ORCID: https://orcid.org/0000-0001-9420-8520 Centro Universitário Fametro, Brasil

E-mail: daysimota1@gmail.com

Héliton Henrique Lima Barbosa

ORCID: https://orcid.org/0000-0002-4249-9490 Centro Universitário Fametro, Brasil

E-mail: heliton.henrique99@gmail.com

Thalia dos Santos Dantas

ORCID: https://orcid.org/0000-0002-6693-3546 Centro Universitário Fametro, Brasil E-mail:thaliadantas022@gmail.com

José Carlos de Sales Ferreira

ORCID: https://orcid.org/0000-0002-1867-8229 Centro Universitário Fametro, Brasil E-mail: jcarlos.sales@gmail.com

Rosimar Honorato Lobo

ORCID: https://orcid.org/0000-0002-8954-2302 Centro Universitário Fametro, Brasil E-mail: rosimar.lobo@ fametro.edu.br

\begin{abstract}
Resumo
Introdução: A banana é originária do extremo oriente e devido a exigência do calor para que seu desenvolvimento seja feito adequadamente, é uma planta típica de lugares com climas tropicais. Por conta do alto nível de carboidratos presentes em sua composição, ela é considerada um excelente alimento de fonte energética, além disso, quando ainda verde, seus níveis de minerais, tais como: potássio, manganês, iodo e zinco são maiores que em seu estado amadurecido. Devido a presença de um amido chamando, "amido resistente", a banana verde apresenta propriedades funcionais semelhantes as fibras alimentares, dessa forma, ajudando na prevenção de doenças degenerativas associadas ao metabolismo intestinal. Objetivo Geral: Afim de descrever os benefícios da utilização banana pacovã verde como um ótimo alimento funcional para o organismo humano. Metodologia: Foi realizado uma pesquisa bibliográfica, com objetivos de identificar a composição nutricional e caracterizar os efeitos do amido resistente, Resultado e Discussão: Descrever os efeitos da utilização da banana verde como alimento funcional, destacar a importância da utilização da banana verde na prevenção e tratamento de doenças crônicas e elucidar a importância da educação nutricional quanto ao conhecimento sobre novas alternativas alimentares. Conclusão: Constatou-se que a banana verde contém vários benefícios, sendo um alimento funcional de baixo custo para população. Dentre as maneiras de utilizá-las, pode-se transformá-la em biomassa.
\end{abstract}

Palavras-chave: Banana verde; Alimento funcional; Amido resistente.

\begin{abstract}
Introduction: The banana originates from the Far East and due to the requirement of heat for its development to be done properly, it is a typical plant in places with tropical climates. Due to the high level of carbohydrates present in its composition, it is considered an excellent food source of energy, in addition, when still green, its levels of minerals such as: potassium, manganese, iodine and zinc are higher than in its state matured. Due to the presence of a starch called, "resistant starch", the green banana has functional properties similar to dietary fibers, thus helping to prevent degenerative diseases associated with intestinal metabolism. General Objective: In order to describe the benefits of using green pacovan banana as a great functional food for the human body. Methodology: A literature search was carried out, with the aim of identifying the nutritional composition and characterizing the effects of resistant starch. Result and Discussion: Describe the effects of using green bananas as a functional food, highlight the importance of using green bananas in prevention and treatment of chronic diseases and elucidate the importance of nutritional education regarding knowledge about new food alternatives. Conclusion: It was found that the green banana has several benefits, being a functional food of low cost for the population. Among the ways to use them, it can be transformed into biomass.
\end{abstract}


Keywords: Green banana; Functional food; Resistant starch.

\begin{abstract}
Resumen
Introducción: El banano es originario del Lejano Oriente y debido al requerimiento de calor para su correcto desarrollo, es una planta típica en lugares con climas tropicales. Debido al alto nivel de carbohidratos presentes en su composición, se considera una excelente fuente de energía alimentaria, además, cuando aún está verde, sus niveles de minerales como: potasio, manganeso, yodo y zinc son más altos que en su estado madurado. Debido a la presencia de un almidón llamado "almidón resistente", el plátano verde tiene propiedades funcionales similares a las fibras dietéticas, lo que ayuda a prevenir enfermedades degenerativas asociadas con el metabolismo intestinal. Objetivo general: Con el fin de describir los beneficios de utilizar el plátano pacovan verde como un gran alimento funcional para el cuerpo humano. Metodología: Se realizó una búsqueda bibliográfica, con el objetivo de identificar la composición nutricional y caracterizar los efectos del almidón resistente. Resultado y Discusión: Describir los efectos del uso del banano verde como alimento funcional, resaltar la importancia del uso del banano verde en la prevención. y tratamiento de enfermedades crónicas y dilucidar la importancia de la educación nutricional en el conocimiento sobre nuevas alternativas alimentarias. Conclusión: Se encontró que el banano verde tiene varios beneficios, siendo un alimento funcional de bajo costo para la población. Entre las formas de utilizarlos, se puede transformar en biomasa.
\end{abstract}

Palabras clave: Plátano verde; Comida funcional; Almidón resistente.

\title{
1. Introdução
}

Grande parte da população mudou ou está tentando mudar seus hábitos alimentares devido à preocupação com a saúde ou com sua aparência física. A busca por alimentos funcionais e de baixo custo que contribuem para a dieta destas pessoas também tem aumentado. A banana pacovã verde tem propriedades funcionais e, além disso, a oferta desta fruta é grande em nosso país e tem um preço relativamente baixo facilitando a inclusão desta fruta em sua alimentação (Pinto \& Dias, 2018).

Raniere e Delani (2014) afirmam que o Brasil se encontra em lugar de destaque na produção, chegando a ser considerado o segundo maior produtor de banana do mundo. Entretanto, o excesso de desperdício ainda é grande devido a técnicas de colheitas inadequadas.

Embora as pessoas não tenham o hábito de consumir a banana ainda verde devido à presença de uma substância chamada tanino, elemento antinutricional que causa adstringência, a fruta verde tem em sua composição uma variedade de vitaminas e minerais que contribuem para que o alimento seja demasiadamente nutritivo, com alto valor energético e rico em amido resitente (Izidoro et al., 2008).

Ao longo deste artigo responderemos de que forma o consumo da banana pacovã verde pode ajudar na prevenção e no tratamento de doenças como Diabetes Melitos, obesidade, problemas cardiovasculares e câncer de cólon, e qual a importância da educação nutricional relacionada ao consumo desta fruta.

\section{Metodologia}

Para a construção desse artigo científico foi utilizada pesquisa de revisão bibliográfica descritiva da literatura. A revisão descritiva propõe a identificação, registro e análise das características, fatores ou variáveis que se relacionam com o fenômeno ou processo (Perovano, 2014). Dessa forma, embasada em referências bibliográficas e científicas, afim de descrever os benefícios da utilização banana pacovã verde como um ótimo alimento funcional para o organismo humano

A literatura cientifica foi baseada em artigos anexados no Google Acadêmico, SciELO, LILACS e PUBMED com períodos de 15 anos que dizem a respeito sobre a biomassa da banana pacovã verde. Pelo fato de haver poucos artigos científicos que abordam sobre da biomassa da banana pacovã verde, foi necessário realizar a revisão bibliográficas de artigos antigos. Foram utilizadas as palavras chaves: biomassa de banana verde, amido resistente, alimento funcional, fibras, a relação do índice glicêmico com a banana pacovã ainda verde, biomassa e seu papel na prevenção de algumas patologias. Foi considerado a busca por descrever os benefícios da utilização banana pacovã verde como um ótimo alimento funcional para a saúde humana. 
Foram utilizados como critérios de escolha deste estudo publicações de artigos científicos disponíveis em platafomas de pesquisa, com a abordagens sobre a biomassa da banana pacovã verde e seus benefícios relacionados à saúde humana. Foram dadas prioridades para os estudos em português.

\section{Resultados e Discussão}

\subsection{A banana pacovã verde e seu Amido Resistente (AR)}

A banana (musa spp.) tem sua origem do oriente e é uma fruta típica de lugares com climas tropicais, pois ela exige calor para que seu desenvolvimento seja feito adequadamente, além de precipitações bem distribuídas (Nascente, Costa \& Costa, 2005).

A banana verde é uma boa fonte de energia devido a presença dos carboidratos. Muito além de um alimento energético, a banana pacovã verde também é rica em vitaminas e minerais como: potássio, manganês, iodo e zinco, vitaminas do complexo B, C e ácido fólico. Os minerais estão em maior concentração quando o fruto está verde. A fruta apresenta poucas quantidades de proteínas como globulina e albumina (Machado \& Sampaio, 2013).

Tabela 1: Tabela nutricional da Banana Pacovã madura e verde crua.

\begin{tabular}{ccc}
\hline \multicolumn{3}{c}{ Quantidade em 100 g. } \\
\hline TABELA NUTRICIONAL \\
\hline Composição & Banana Madura & Banana Verde \\
\hline Calorias & $95 \mathrm{kcal}$ & $122 \mathrm{kcal}$ \\
Carboidrato & $22 \mathrm{~g}$ & $28,70 \mathrm{~g}$ \\
Gordura & $0,20 \mathrm{~g}$ & $0,20 \mathrm{~g}$ \\
Proteína & $1,30 \mathrm{~g}$ & $1,40 \mathrm{~g}$ \\
Vitamina A (Retinol) & $23 \mathrm{mcg}$ & $25 \mathrm{mcg}$ \\
Vitamina B1 (Tiamina) & $57 \mathrm{mcg}$ & $40 \mathrm{mcg}$ \\
Vitamina B2 (Riboflavina) & $80 \mathrm{mcg}$ & $76 \mathrm{mcg}$ \\
Niacina & $1,18 \mathrm{mg}$ & $0,44 \mathrm{mg}$ \\
Vitamina C & $6,40 \mathrm{mg}$ & $16,90 \mathrm{mg}$ \\
Cálcio & $21 \mathrm{mg}$ & $8 \mathrm{mg}$ \\
Ferro & $1,06 \mathrm{mg}$ & $0,90 \mathrm{mg}$ \\
Fósforo & $26 \mathrm{mg}$ & $35 \mathrm{mg}$ \\
\hline
\end{tabular}

(*) \% Valores Diários de Referência com base em uma dieta de 2.000 kcal ou de 8400 kj. Seus valores diários podem ser maiores ou menores dependendo de suas necessidades energéticas. Fonte: Franco (1992). 
Tabela 2: Exame físico-químico da polpa de banana verde cozida.

\begin{tabular}{cc}
\hline Teste & Resultado \\
\hline Umidade & $77,00 \%$ \\
Proteínas & $10,80 \%$ \\
Lipídeos & $1,32 \%$ \\
Fibra bruta & $1,98 \%$ \\
Cinzas & $0,70 \%$ \\
Amido & $6,30 \%$ \\
Açucares totais & 0 \\
\hline
\end{tabular}

Fonte: ITAL- Instituto de Tecnologia de Alimentos, Banana: Série Frutas Tropicais (1990).

Uns dos itens presentes na banana pacovã verde é o amido resistente (AR). O amido resistente está presente nela ainda verde, visto, que a prudência qual acontece o amadurecimento, ele é revestido em açúcares como dissacarídeos (Machado \& Sampaio, 2013).

O termo manteve-se frequente a partir de decenio de 80 por Englyst cooperador (1982), com experimentação científicos com polissacarídeos não amido. Eles espreitaram que, após a hidrólise enzimática, uma parte do amido ainda avançava inteira. Exclusivamente no decênio de 90 que o amido resistente (AR), destinou-se a decidir de que modo a abundância integral de amido dele volume de degradação que sobrevive a digestão nas vísceras do chato das pessoas sadias (Santos et al., 2010).

O (AR) é dividido em quatro tipos: AR1, AR2, AR3 e AR4. O tipo AR1 é fisicamente dificil, portanto localiza-se hoje em grãos e sementes que são parcialmente trituráveis devido à presença de paredes celulares rígidas. O tipo AR2 é encontrado embatatas cruas e bananas verdes. O AR3 surge a partir do processo de retrogradação doamido, encontrado em alimentos processados, cozidos e resfriados. Já o tipo AR4 é o amido quimicamente modificado (Salgado et al., 2005).

$\mathrm{O}$ amido resistente pode apresentar propriedades funcionais semelhantes às fibras alimentares que ajudam na prevenção de doenças degenerativas associadas ao metabolismo intestinal. Em termos fisiológicos, o amido resistente é definido como a soma do amido e o produto da sua degradação não é digerido no intetino delgado de indivíduos sadios. Sendo assim, essa fração de amido se comporta da mesma forma que as fibras alimentares (Lobo \& Silva, 2003).

A banana pacovã verde por ser rica em amido resistente, tem um enorme potencial na prevenção de comorbidade crônicas não transmissíveis como a diabetes tipo 2 e um poder de saciedade que o torna um alimento importante em dietas que combatem a obesidade e colesterol elevado (Oliveira et al., 2015)

O consumo de amido resistente depende de um país para o outro, como por exemplo, na China em que o consumo diário é de 18g/dia, na União Europeia é de 3 a 6 g/dia. SCIRO (Organização de pesquisa científica e industrial da Austrália) recomenda o consumo de aproximadamente 20g/dia de AR (Santos et al., 2010).

\subsection{A banana pacovã verde como alimento funcional}

Alimentos funcionais são produtos alimentares que, em sua composição, contém componentes biologicamente ativos que promovem efeitos fisiológicos e metabólicos importantes para o ser humano resultando na diminuição dos riscos de desenvolver várias doenças e ainda contribui para o aumento da saciedade (Ribeiro et al., 2012).

Segundo Vidal (2012) tais efeitos de um alimento funcional ainda é muito estudado em algumas patologias, como câncer, diabetes, hipertensão e entre outros.

A resolução $\mathrm{N}^{\circ} 18$ da ANVISA define alimentos funcionais como: 
O alimento ou ingrediente que alegar propriedades funcionais ou de saúde e que pode, além de exercer funções nutricionais básicas, quando se tratar de nutriente, produzir efeitos metabólicos e ou fisiológicos e ou efeitos benéficos à saúde, devendo ser seguro para consumo sem supervisão médica (Anvisa, 199 p.3)

Quando cozida, a banana pacovã verde assume atividades funcionais em forma de probiótico, pois possui em sua composição os dois tipos de fibras, solúveis e insolúveis, desenvolvendo boas funções ao organismo humano. Os alimentos probióticos, como a banana pacovã verde, são definidos como alimentos que resistem ao processo de digestão, sendo fermentados, então, pelas bactérias que estão presentes no intestino e estimulando o seu desenvolvimento (Leon, 2010).

As fibras alimentares são consideradas carboidratos com número de meros igual ou acima de três, isso significa que não podem ser digeridos e nem absorvidos no intestino delgado.

As fibras solúveis são digeridas pelas enzimas que as quebram, na presença de água, na parte superior do trato gastrointestinal. As insolúveis têm o processo de digestão mais lento, que é feito pelas bactérias anaeróbias, as quais produzem ácidos graxos de cadeia curta e gases (Saad, 2006).

As fibras alimentares são de grande relevancia nutricional. Na África, aonde oconsumo de fibras na dieta chega a 150 g/dia, a população, em média, não apresentadoenças como diverticulite e constipação. Já no Brasil a população consome poucas fibras, principalmente nas cidades metropolitanas onde a rotina do dia influencia negativamente nos hábitos alimentares dos brasileiros e, na maioria das vezes, ocorre um consumo maior de comidas industrializadas do que de alimentos naturais (Bueno,2015)

A polpa da banana pacovã verde, conhecida como biomassa, caracteriza-se por conter alto teor de amido, baixos teores de umidade, de açúcares e compostos aromáticos (Izidoro, 2007). A biomassa de banana pacovã verde não é utilizada somente como ingrediente principal das formulações alimentícias, mas também como coadjuvante funcional, em substituição aos espessantes produzidos à base de trigo, soja, fécula de mandioca e amido de milho. Quando a poupa é tranformada em biomassa, os taninos presentes na banana verde, responsáveis pela adstringência, são removidos. Isso facilita sua introdução nos alimentos, não modificando o sabor. Sua incorporação ainda melhora a qualidade dos produtos no que diz respeito a parte nutricional, pelo alto conteúdo de fibras, além disso, a preparação com a biomassa rende mais e ainda atua como espessante, devido ao alto teor de amido (70 a 80\%) (Ormenese, 2010; Kenji, Basile \& Tambourgi; Moraes Jr, 2010; Ranieri \& Delani, 2018).

Segundo Vernaza et al., (2011), a produção de farinha de banana verde (FBV) encontra ampla aplicação na indústria de alimentos, principalmente na elaboração de produtos de panificação, produtos dietéticos e alimentos infantis, sendo uma fonte de amido resistente e sais minerais, tais como potássio, cálcio, ferro, magnésio e enxofre. Além dos benefícios nutricionais, a produção de FBV contribui na redução das perdas pós-colheita, aumento do tempo de vida de prateleira e na agregação de valor à fruta (Bezerra et al., 2013).

A banana é uma fruta que tem valor nutricional considerável, é energética, rica em minerais como: potássio, manganês, iodo, zinco e vitaminas do complexo B, além disso, tem ótima sazonalidade e baixo custo. Ela contém um nutriente essencial, que é amido resistente (AR), conforme ocorre o processo de amadurecimento, esse amido é convertido em dissacarídeos, por isso a importância da produção da biomassa com afruta ainda verde (Ranieri et al., 2014).

\subsection{Os benefícios da utilização da banana pacovã verde no que diz respeito ao seu papel na prevenção e tratamento de doenças}

Os alimentos que são fontes de carboidratos também contêm vitaminas e minerais, além de outros nutrientes importantes, como fito químicos e componentes antioxidantes. Os carboidratos podem ser digeridos e absorvidos em 
velocidades diferentes no trato gastrointestinal e isso está relacionado com a própria característica do alimento. A velocidade na qual o alimento será absorvido influenciará na resposta glicêmica de formas diferentes no organismo (Menezes et al., 2011).

$\mathrm{O}$ amido resistente presente na banana ainda verde contribui para a queda dos índices glicêmicos dos alimentos, proporcionando uma menor resposta glicêmica e, consequentemente, uma menor resposta insulínica, auxiliando no tratamento da diabetes tipo 2. Além de ajudar a controlar a diabetes tipo 2, o amido resistente também pode contribuir para a diminuição do risco de desenvolver e tratar outras doenças crônicas (Basso et al., 2011)

Os ácidos propiônicos, produto de fermentação do amido resistente pelas bactérias, têm duas funções muito relevantes: a melhora da contração muscular do cólon, elevando o peristaltismo intestinal contribuindo para a redução da obstipação, e a diminuição da síntese de colesterol nos hepatócitos, diminuindo o risco de doenças relacionadas ao coração (Salgado et al., 2005).

O consumo da banana pacovã verde também estimula a função da mucosa intestinal, que exerce um efeito importante na integridade do próprio intestino. Esta mucosa protege o intestino das constantes exposições aos microrganismos patológicos dos alimentos e do meio ambiente e pode ser fortificado através do consumo da fruta por agir como um probiótico que serve como base para a produção de butirato, que é ácido graxo de cadeia curta (AGCC) que serve como fonte energética para o desenvolvimento dos colonócitos (INCA, 2014).

Outras doenças crônicas como a obesidade também podem ser evitadas ou controladas com hábito de fazer a ingestão da banana pacovã verde, seja ela em biomassa ou em farinha. O aumento de peso e as DCNTs (doenças crônicas não transmissíveis) estão se agravando. A obesidade vem sendo estudada como um estado inflamatório crônico em associação com diversas outras doenças crônicas, comoaDiabetes Mellitus e doenças cardivasculares, sendo o desequilíbrio da ingestão de micronutrientes uma das principais causas dessa comorbidade (Silva et al., 2015).

A obesidade é uma doença de início multicausal, a ação para corrigi-la deve ser

multidisciplinar. A dietoterapia é extremamente para ajudar no seu tratamento, assim como exercícios físicos, a psicoterapia e drogas anorexígenas, mas nem sempre o sucesso na perda de peso é alcançado, mesmo com várias opções terapêuticas (Dâmaso et al., 2006; Kovalesk et al., 2016). A banana pacovã verde pode ajudar na diminuição do peso, pois ela tem um efeito sacietogênico, além de ajudar a combatero colesterol elevado (Oliveira et al., 2015).

Pelo fato de o amido resistente se comportar como as fibras, um dos benefícios é o aumento do bolo fecal, isso ajuda a previnir a constipação e outras doenças, além de diminuir compostos tóxicos provocados pelas células cancerígenas (Emanuelli et al., 2005)

\subsection{Como é feita a biomassa da banana pacovã verde?}

A biomassa da banana verde é basicamente uma preparação homogênea que é muito utilizado como espessante e, por não conter gosto, é usada em muitas receitas. Quandoincluída em alguma receita, aumenta seu valor nutriconal e a sua consistência. A biomassa pode ser prepara de três tipos: biomassa $\mathrm{P}$ (poupa), biomassa $\mathrm{F}$ (casca verde)e a biomassa integral (utiliza-se a casca e a poupa) (Ribeiro et al., 2012). O tipo de biomassa abordada neste artigo é o tipo P (poupa).

Para que a biomassa da banana seja obtida, devemos primeiro escolher bananas pacovãs verdes. Lave-as ainda com as cascas utilizando água corrente e esponjas. Após, coloque-as em na panela de pressão acrescentando água até cobrir as frutas e deixe cozinhar por 20 minutos. Depois de cozidas, retire as cascas e processe as poupas das bananas no liquidificador até obter uma pasta homogenia (Dinon \& Devitte, 2011) 


\subsection{A importância da educação nutricional quanto ao conhecimento sobre novas alternativas alimentares}

O processo de Educação Nutricional pode ser definido como um conjunto de atividades que visa a formação ou mudança de hábitos alimentares saudáveis, isto implica em uma enorme mudança que se vincula as práticas e atitudes diárias do indivíduo (Souza, 2006).

Educação Nutricional é um campo de conhecimento e de prática contínua e permanente, transdisciplinar, intersetorial e multiprofissional que visa promover a prática autônoma e voluntária de hábitos alimentares saudáveis. A prática de EAN deve fazer uso de abordagens e recursos educacionais problematizadores e ativos que favoreçam o diálogo junto a indivíduos e grupos populacionais, considerando todas as fases do curso da vida, etapas do sistema alimentar e as interações e significados que compõem o comportamento alimentar. (Brasil, 2012).

A prática de EAN, segundo o Marco de EAN, deve considerar as interações e significados que constituem o comportamento alimentar. Nesse sentido, apresenta dois princípios para ações: 1) valorização da cultura alimentar local e respeito à diversidade de opiniões e perspectivas, considerando a legitimidade dos saberes 24 de diferentes naturezas; 2) comida e alimento como referências: valorização da culinária enquanto prática emancipatória. Ambos os princípios expressam a dimensão cultural do alimento. Reconhecem que as escolhas alimentares se relacionam com visões de mundo, com a formação da identidade de povos e grupos sociais, com o processo histórico de constituição da nacionalidade, marcado pela riqueza e variedade dos alimentos e preparações, que são expressão da contribuição de diferentes povos na formação cultural brasileira.

No que se refere aos hábitos alimentares, baixa ingestão de fibras, vitaminas e minerais é uma constante na população brasileira. Na tentativa de se elevar o consumo desses nutrientes, várias alternativas têm sido propostas, como o emprego de novos ingredientes em alimentos tradicionais. $\mathrm{O}$ uso de farinha de banana verde, além de adicionar valor nutricional aos produtos alimentares, possui potencial promissor na preparação de alimentos para pacientes com inflamação intestinal e com doença celíaca (Voragen,1998; Fasolin et al., 2007, Bezerra et al., 2013).

Tais subprodutos podem ser amplamente utilizados na culinária, graças às características de um de seus principais componentes (o amido resistente) que funciona como um agente espessante para preparações de doces e salgados, sem afetar sua palatabilidade e melhorando o valor nutricional dos alimentos. A farinha, por exemplo, pode ser utilizada na linha de produtos panificáveis em substituição parcial à farinha de trigo (Lobo \& Silva, 2003; Poiani et al., 2009; ovandro-Martinez, 2009), pré-misturas de bolo (borges et al., 2010), biscoitos (Fasolin et al.,2007) e podem ser citados ainda outros produtos, como suco tropical enriquecido com polpa de banana verde (Taipina et al., 2004; Silva \& Araújo, 2009), e em emulsões tipo maionese (Izidoro et al., 2008). 
Folheto 1: O que é e quais os benefícios da biomassa de banana pacovã verde.
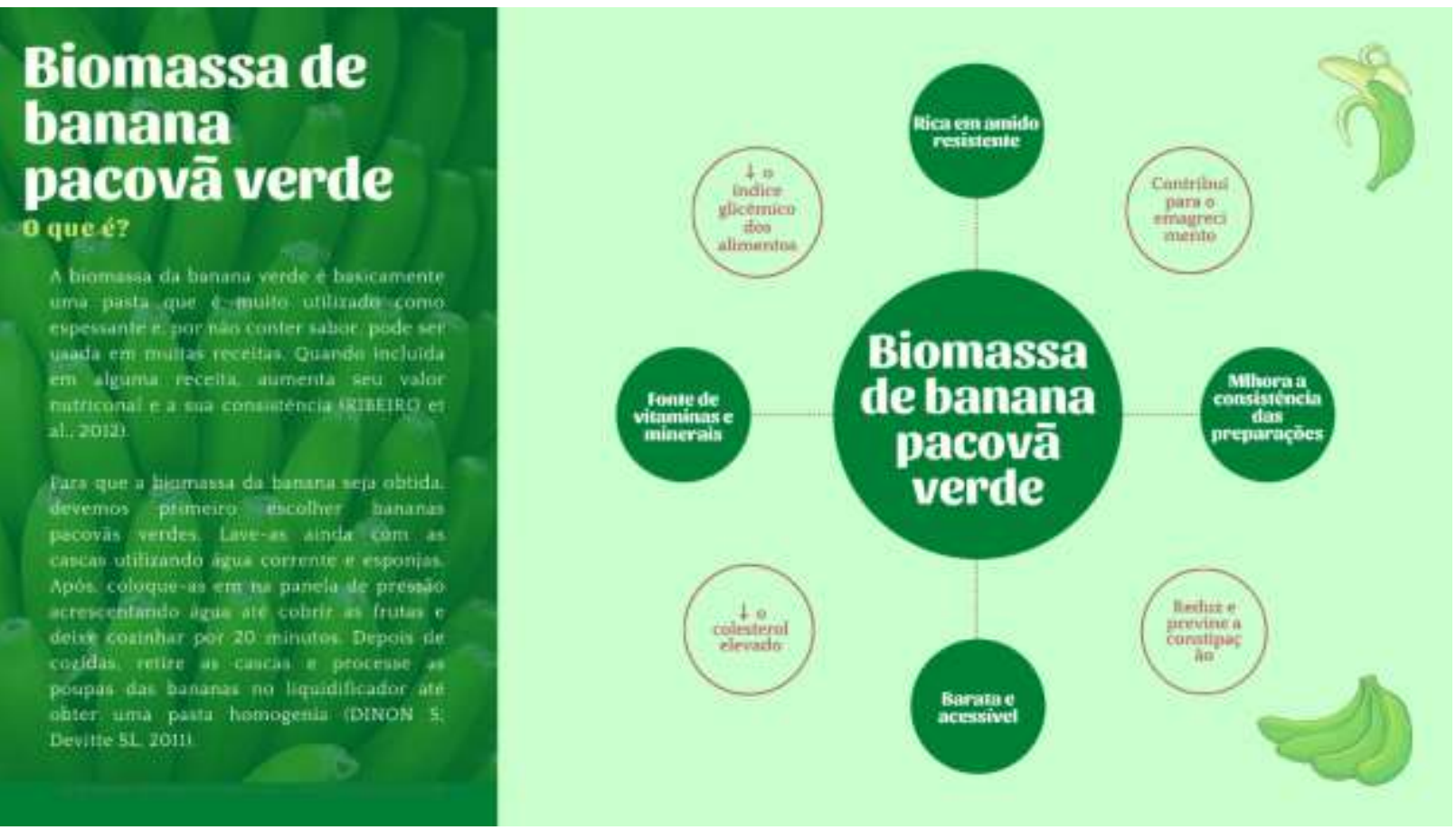

Fonte: Autores.

Folder 1: Conceito e benefícios da biomassa da banana pacovã verde.

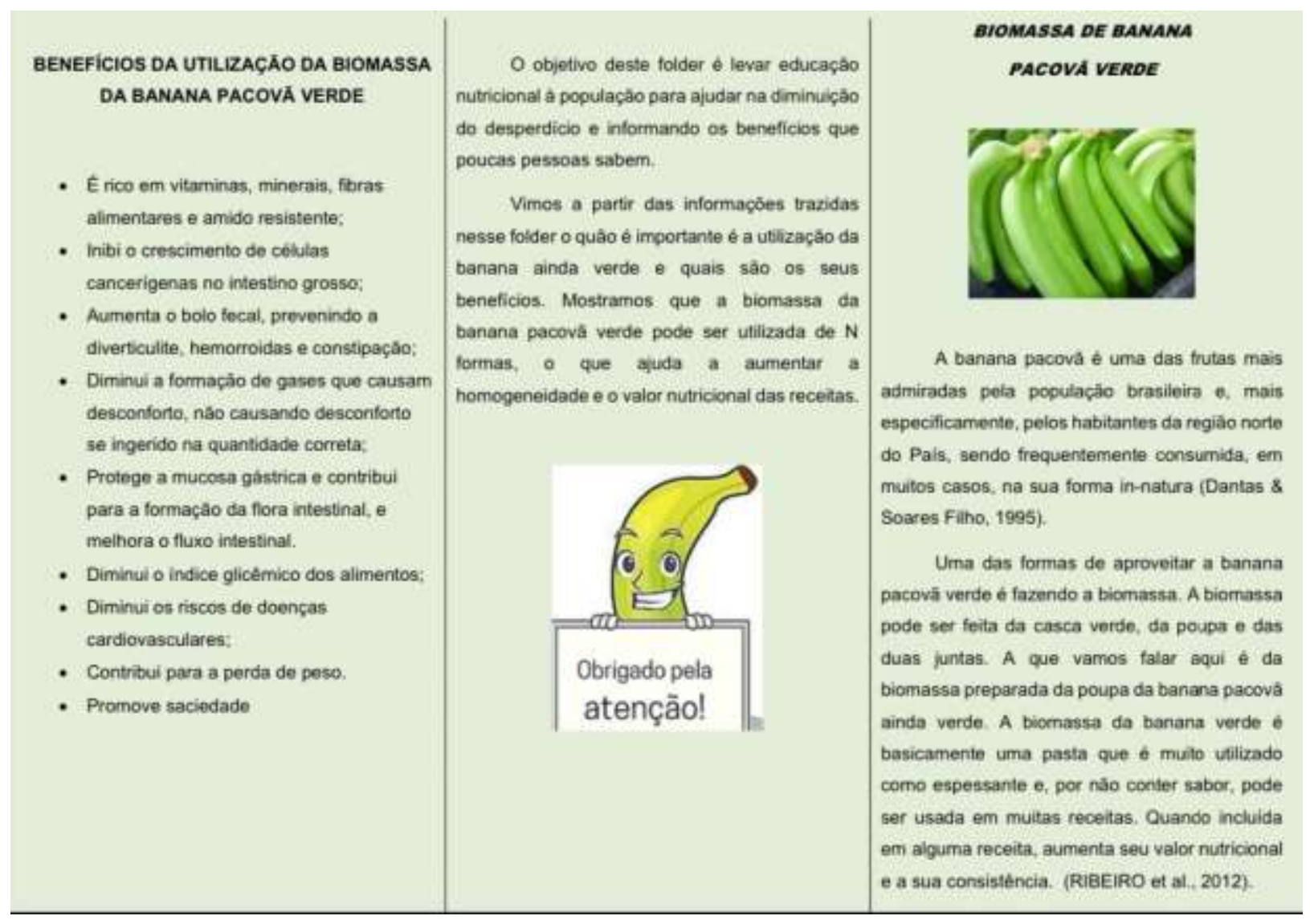

Fonte: Autores. 
Folder 2: Receita da biomassa da banana pacovã verde.

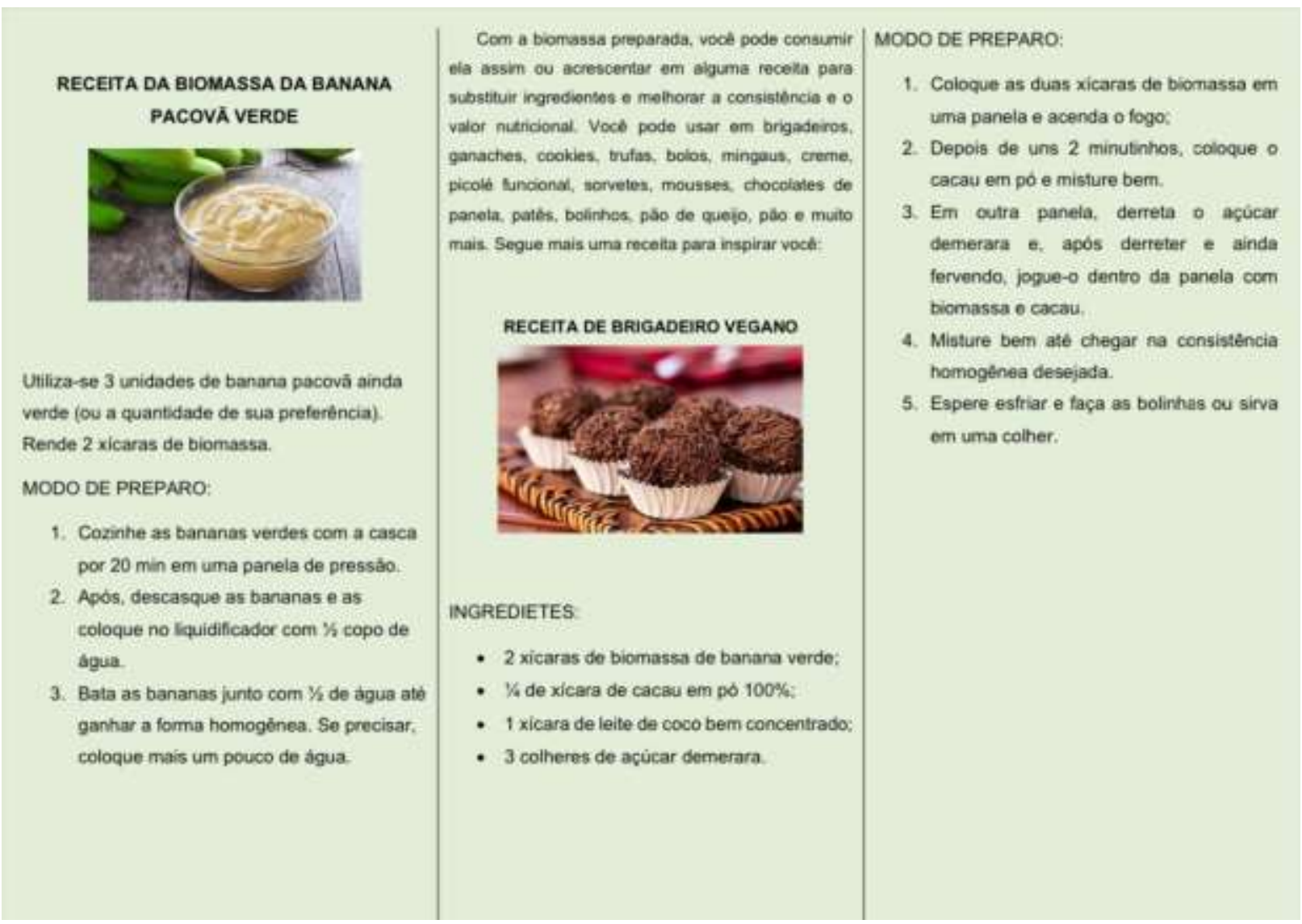

Fonte: Autores.

\section{Conclusão}

O Brasil, com uma área cultivada de 2,2 milhões de hectares, é considerado um grande produtor mundial de frutas, produzindo cerca de 30 milhões de toneladas anuais.

A fruticultura praticada no Nordeste do Brasil pode ser considerada, atualmente, uma das principais atividades agrícolas. Nesse contexto, merece destaque a fruticultura irrigada, existindo, hoje, quatorze polos de irrigação em franco desenvolvimento, nos quais a cultura da bananeira apresenta destacada importância socioeconômica.

A banana pacovã verde encontra, nos projetos irrigados do Nordeste brasileiro, condições edafoclimáticas das mais favoráveis, registrando-se, em algumas cultivares, produtividade superior a 80 tlha/ano (Barreto, 1988).

A banana é hoje cultivada, quase sem exceção, em todos os Projetos Irrigados públicos e privados do Nordeste.

Em geral, podemos concluir que a banana pacovã verde, é uma fruta muito cobiçada nos 4 cantos desse Brasil a fora, mas porquê mesmo? No artigo especificamos o motivo dessa fruta ser tão adorada e receitada por nutricionistas para aqueles casos em que gostaríamos de adentrar uma refeição saudável no nosso dia a dia.

A própria é doce é muitas vezes substituída por uma sobremesa cheia de carboidratos ou gorduras que ocasiona de até causa uma diabete no futuro ou outra doença. A fruta contém proteínas e é rica em vitaminas que compõem uma arisca fonte de biomassas que institui o corpo a ser mais forte e ter uma imunidade mais persiste e coasivel. Em relação aos benefícios para pele, muitas esteticistas utilizam da banana, mamão e abacate como fonte contra Melasma e outras doenças de pele. Sem contar de ser um antioxidante natural que purifica a pele e regenera rugas anti-idade.

Com isso, concluímos que a banana pacovã se faz bem de dentro para fora, por conta de tantos nutrientes que a fruta proporciona. 


\section{Referências}

ANVISA, Agencia Nacional de Vigilância Sanitaria. 1999. <http://portal.anvisa.gov.br/>.

Basso, C., Silva L. P., Bender, A. B. B., \& Silveira, F. (2001). Elevação dos níveis de amido resistente: efeito sobre a glicemia e na aceitabilidade do alimento. Rev Inst Adolfo Lutz, 70(3), 276-82.

Bianchi, M. (2011). Banana verde - propriedades e benefícios. 2011. htt://www.valemaisalimentos.com.br/material/bananaverde propriedades_e_beneficios.pdf.

Dâmaso, A. R., et al. (2006). Tratamento multidisciplinar reduz o tecido adiposo visceral, leptina, grelina e a prevalência de esteatose hepática não alcoólica (NAFLD) em adolescentes obesos. Rev Bras Med Esporte, São Paulo, 12(5), 263-267.

Dantas, J. L. L., \& Soares Filho, W. S. (1995). Banana para exportação: aspecto técnico da produção. Secretaria de Desenvolvimento Rural. Programa de Apoio à Produção e exportação de Frutas e Hortaliças, Flores e Plantas Ornamentais-FRUPEX, 9.

Dinon, S., \& Devitte, S. L. (2011). Mortadela adicionada de fibras e com substituição parcial de gordura por carragena e pectina. Trabalho de diplomação apresentado como requisito parcial de avaliação para obtenção da grade Tecnólogo, no Curso Superior de Tecnologia em Alimentos, da Universidade Tecnológica Federal do Paraná-UTFPR. Medianeira.

Emanuelli, T., Silva, L. P., \& Walter, M. (2005). Amido resistente: características físico-químicas, propriedades fisiológicas e metodologias de quantificação. Ciência Rural.

INCA (Instituto Nacional de Câncer). 〈http://www2.inca.gov.br/wps/wcm/connect/cancer/sit e/oquee>

Izidoro, D. R. (2007). Influência da polpa de banana (Musa cavendishii) verde no comportamento reológico, sensorial e físico-químico de emulsão. <https://www.acervodigital.ufpr.br/bitstream/handle/1884/8456/disserta\%E7\%E3o\%20final.pd f?sequence=1>

Kovaleski, E. S., et al. (2016). Perfil farmacoterapêutico de pacientes obesos no pósoperatório de cirurgia bariátrica. Jornal Vascular Brasileiro, [s.1.], 15(3), 182-188. FapUNIFESP (SciELO). http://dx.doi.org/10.1590/1677-5449.002016.

Leon, T. M. (2010. Elaboração e aceitabilidade de receitas com biomassa da banana verde. Trabalho de conclusão de curso- Universidade do extremo Sul Catarinense.

Lobo, A. R, \& Silva, G. M. L. (2003). Amido resistente e suas propriedades físico-químicas. Rev. Nutr.

Machado, N. C. R., \& Sampaio, R. C. (2013). Efeitos do amido resistente da biomassa da banana verde. Artigo apresentado no V seminário de pesquisa e TCC da Faculdade União Goyazes, Goiás. http://wwwfug.edu.br/2010/pdf/tcc/efeitos do amido resistente da biomassa da banana verde.

Menezes, E. W., Dan, M. C. T., Giuntini, E. B., Fukumori, C., \& Lajolo, F. M. (2011). Efeito do consumo de farinha de banana verde sobre o perfil de hormônios gastrintestinais relacionados à saciedade. Nutrire. 36, 67.

Nascente, A. S., Costa J. N. M., \& Costa, R. S. C. (2005). O cultivo da banana verde em Rondônia. 2005. http://sistemasdeproducao.cnptia.embrap a.br/FontesHTML/Banana/CultivodaBananaRO/autores.htm.

Oliveira, C. R., Santos, M. B., \& Santos, M., F. G. (2016). O Potencial da Biomassa de Banana Verde na Simbiose Intestinal. Revista ciência e sociedade, Macapá, 1,1 .

Oliveira, D. A. S. B., et al. (2015). Avaliação da qualidade de pão com adição de farinha e purê da banana verde. Rev. Bras. Frutic, Jaboticabal, 37(3), 699707.

Pereira, K, D. (2007). Amido resistente, a última geração no controle de energia e digestão saudável. Revista Ciência Tecnologia e Alimento, $27,88-92$.

Perovano, D. G. (2014). Manual de Metodologia Científica. Paraná: Editora Juruá.

Ranieri, L. M., \& Delani, T. C. O. (2014). Banana verde: Obtenção da Biomassa e Ações Fisiológicas do Amido Resistente. Revista Uningá review, 20(3), 4349.

Ribeiro, C. M., Martins, J. F. L., Paula, H. A. A., \& Ferreira, C. L. L. F. (2012). Potencial probiótico e tecnológico das bactérias do ácido lático no desenvolvimento de embutido cárneos fermentado. Rubio, 2012.

Ribeiro, C. M., Martins, J. F. L., Paula, H, A, A., \& Ferreira, C. L. L. F. (2012). Potencial probiótico e tecnológico das bactérias do ácido lático no desenvolvimento de embutido cárneos fermentado. Rubio. Rio de janeiro.

Saad, S. M. I. (2006). Probióticos e prebióticos: o estado da arte. Revista brasileira de Ciências Farmacêuticas. 42(1), 1-16.

Salgado, S. M., Faro, Z. P., Guerra, N. B., \& Oliveira, A. V. S. (2205). Aspectos físico-quimico do amido resistente. B. ceppa. 23(1), 109-122

Santos, J. C., Silva, G. F., Santos, J. A. B., \& Junior, A. M. O. (2010). Processamento e avaliação da estabilidade da banana verde. Rev. Excata. 8(2), 219-24

Silva, T. M., et al. (2015). Coacervação complexa: uma técnica para a encapsulação de probióticos. Revista do Centro de Ciências Naturais e Exatas, Santa Maria, 37, 49- 55

Vidal, A. M., et al. (2012). A ingestão de alimentos funcionais e sua contribuição para a diminuição da incidência de doenças. Aracajú- SE: Cadernos de Graduação: Ciências Biológicas e da Saúde. 1(15), 43-52. 